\title{
絭 \\ Incorporation of the socio-cultural dimension into strategic long-term planning of mineral assets in South Africa
}

\author{
by G.L. Smith* and L. Brooks ${ }^{\dagger}$
}

\section{Synopsis}

Extraction of minerals and metals has had, and continues to have, material impacts on society. These impacts can be positive, enabling technological innovation and stimulating economic development, as well as negative, such as environmental and social impacts. The inability to effectively manage these impacts throughout the life of mine (LoM) plan can trigger socio-cultural risks. In fact EY (formerly Ernst \& Young) have ranked the social licence to operate as one of the top five risks to the mining sector globally since 2008 (EYGM, 2016).

Strategic long-term planning for mineral assets enables delivery of an optimized, strategically aligned business plan from a mineral asset portfolio using a set of tools and techniques with a common language, standards, systems, and processes to align decisions and actions on a cyclical basis. The framework provides the basis for effective management of large, diverse, and complex mineral asset portfolios while creating shared understanding and a common language. It is an approach that acknowledges the nature of the depleting mineral asset base, the importance of a defined but flexible project pipeline, variability in market conditions, and the requirements of the operating legislative environment.

However, effective integration of social and environmental considerations into strategic and project planning still remains a challenge for the industry, where social performance considerations manifest predominantly as constraints rather than as optimization objectives.

This paper considers the inherent opportunities and challenges in the effective integration of social performance issues into strategic long-term planning for mineral assets in South Africa. It also sets out Anglo American's approach to integrating socio-cultural issues into LoM and resource development planning (RDP) to ensure that operations are able to secure and maintain an effective social license to operate (SLTO) as well as deliver a lasting positive contribution to local communities.

Keywords

strategic planning, socio-cultural issues, impact management.

\section{Context}

Mining has a substantial impact on and importance for both local socio economic development and national economic stability in many countries. The benefits of mining arise directly from financial investment and project development activities, ongoing operations, infrastructure development, employee remuneration, and taxation and royalties paid to the government and communities. Further indirect benefits arise from the multiplier effect due to local business development associated with mining operations (for example support industries, catering, and accommodation establishments) and the associated cash flow and employment benefits to the local community. The positive economic effects of a mine in a community can extend beyond local employment opportunities and supplier development programmes, to enterprise development, the development of local and regional health care facilities, transport infrastructure, water and electricity distribution infrastructure, agricultural activities, educational services, and community cultural activities. At a national level, apart from contributions to the national fiscus through taxes and royalties, the minerals industry contributes to foreign exchange earnings, technological advances, and the development and transfer of skills across the economy.

In contrast to the many positive effects of mining at the national level, extractive practices are often associated with costs related to adverse environmental, social, and cultural impacts at the local level. Mining inherently requires large areas of land to operate and the physical impacts of developing and operating a mine often cause stress on the natural environment and ecosystems. In some cases, the development of mining operations can trigger social impacts - such as involuntary resettlement (including physical and economic displacement), criminal activity, social dislocation, inflationary pressures, impacts on services (health, education, water, sewerage), communicable diseases, and gender-based violence etc., as well as and environmental impacts such as dust, erosion, vibration, and noise and water pollution. Development in previously undeveloped rural

\footnotetext{
* Anglo American Platinum Limited, South Africa.

$\mp$ Anglo American plc, South Africa.

(C) The Southern African Institute of Mining and Metallurgy, 2018. ISSN 2225-6253. This paper was first presented at the 7 th International Platinum Conference 2017 'Platinum-A Changing Industry' In Association with AMI Precious Metals 2017, 18-19 October 2017, Protea Hotel Ranch Resort, Polokwane, South Africa.
} 


\section{Incorporation of the socio-cultural dimension into strategic long-term planning of mineral assets}

areas with low per capita income can lead to negative effects on local social and cultural practices, by physically altering traditional land use areas and through increased financial inequalities resulting from employment at mining operations.

Given the wide range of potential positive and negative impacts of mining, inter- and intra- community conflicts can arise in relation to the appropriate distribution of costs and benefits. While economic benefits accrue to a small portion of the community (the mining operation cannot employ everybody), the majority experience negative environmental, social, and cultural impacts. Compounding this complex situation is the number of entities or groupings with interests in the mine development process, for example representatives of local communities, and municipal, district, regional, provincial, and national and non-governmental organizations. The number of vested interests and opinions increases the complexity of engaging and developing appropriate solutions that are both legitimate and costeffective.

These conflicts of interest arise within communities as well as between communities and mining companies. Conflict, in turn, can lead to the disruption of mining operations through protests, and damage to mining equipment and infrastructure which, subsequently, has an adverse impact on the profitability of the operation and the continuation of such operations. The closure or suspension of mining operations as a result of community disruption, in turn, has negative consequences for local communities due to the loss of wages, the closure of small businesses, and the general contraction of economic activities.

Against this backdrop, sustainable development, effective social performance management, negotiating conflicting interests, and eliciting local support are a high priority for both mining businesses and government.

It is thus fair to say that early, effective integration of social and environmental considerations into mineral asset development planning remains a major challenge for the minerals and metals industry. This integration needs to start during exploration and continue throughout the life of mine (LoM), including project development, construction, operation, and closure.

\section{Strategic long-term planning}

For a minerals and metal company to create sustainable value from mineral assets, it is necessary to:

> Optimize the composition of the mineral asset portfolio to align with strategic and business objectives

> Create and operate long term-assets within an anticipated long-term business environment

> Create and retain a flexible, short-term tactical approach that allows effective response to short-term shifts in the business environment, i.e. a production mix that allows variation of output in response to short-term market variation, within a long-term context.

Thus, the fundamental challenge facing mineral and metal companies is how to create sustainable value while operating within mandated strategic bounds, identified constraints, and variable market and economic conditions (Smith, 2012).
This outcome is achieved in practise through strategic long-term planning. The strategic long-term planning framework is a logic construct that enables delivery of an optimized, strategically aligned business plan from the mineral asset portfolio using a set of tools and techniques with a common language, standards, systems, and processes to align decisions and actions on a cyclical basis.

This can be achieved by:

- Allowing the fixed physical nature of the mineral asset(s) to drive definition of the optimal (lowest capital cost, lowest operating cost, highest efficiency, maximized cash flow) technical solution to mining and recovery activities

> Defining and applying different business environment perspectives, world views, or scenarios, to determine possible economic viability under the different perspectives, i.e. define the value proposition under different scenarios - what are the options?

> Developing and resourcing a strategically aligned portfolio of production entities from the mineral asset portfolio that enables flexibility to cope with near- and longer-term business environment shifts, i.e. creating a production mix that allows variation of output (minerals/metals, operating cost, capital intensity) in response to market demand and pricing.

This approach and the interrelationship between elements is represented schematically in Figure 1.

Interpreting Figure 1 from the bottom left upwards:

- The global and national business environments, in conjunction with the characteristics of the market for mining product(s), create the context in which world views or scenarios are developed for application in planning. Critically, this is creating the understanding of the business environment in which the mining company operates and also understanding of the key drivers of change from one economic state to the next.

> World views or scenarios (the centre link part of the diagram), inclusive of the socio-cultural dimension, are developed and used to develop long-term planning parameters ('global assumptions') that represent the relevant underlying assumptions for each scenario, e.g. metal prices, exchange rates, escalation, etc. These planning parameters inform the financial analysis and optimization of the business plan, and create the link between mineral asset portfolio utilization and the market.

> The annual cyclical business planning process is conducted utilizing the planning parameters (global assumptions) associated with the preferred, or most likely, world view. The physical characteristics of the individual mineral assets within the portfolio determine the development of a mine's extraction strategy, the mining right plan, the budget, and long-term plan per asset and collectively for a multi-asset business. Concurrently, value is optimized through application of value-based management principles - at mineral asset level and company level for a multi-asset organization.

> The composition of the mineral asset portfolio is then reviewed and optimized relative to the most likely scenario, the current state of execution of projects, and company's strategic intent. 


\section{Incorporation of the socio-cultural dimension into strategic long-term planning of mineral assets}

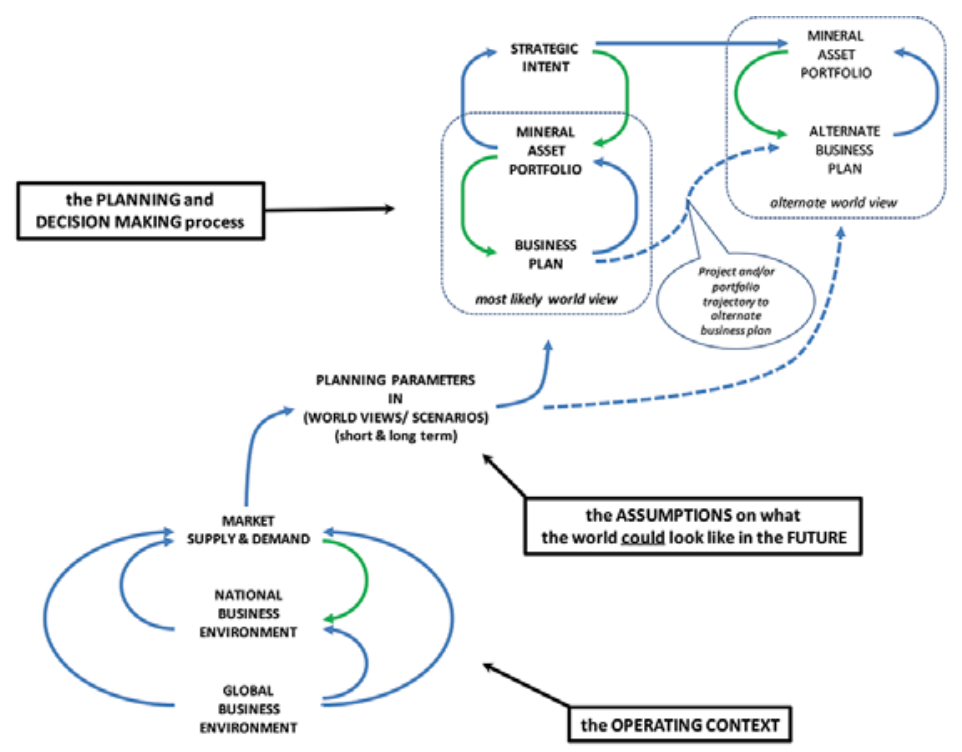

Figure 1-Schematic representation of the relationship between key strategic long-term planning elements (after Smith, 2012)

The business plan, which is the core output of the strategic long-term planning process, is then reassessed for a possible shift to the next most likely world view. Real options arising from evolving alternative trajectories are evaluated and a contingency plan is developed, based on planning parameters associated with the alternate scenario.

The business plan then forms the basis upon which the organization is structured and resourced. Supporting, aligned execution plans are developed for the necessary supporting activities in finance, human resources, projects, engineering and infrastructure, and sustainable development. All of these activities take place in a regular planning cycle.

\section{The global business environment and mining business risk}

It is becoming increasingly evident that the strategic longterm planning for an asset cannot be done in isolation from the broader global operating context. Social and environmental issues or conflicts are significantly affecting the delivery of strategic projects across the minerals industry. The EY (formerly Ernst \& Young) Business Risks report, (EYGM, 2016) indicates that the social licence to operate remains in the top five risks for the mining and metals industry (Figure 2).

Within this context, early, effective integration of social and environmental considerations into mineral asset development planning remains a major challenge for the minerals and metals industry. As stated previously, this integration needs to start during exploration and continue throughout the LoM, including project development, construction, operation, and closure.

\section{The projects perspective}

Taking a broader minerals industry perspective and considering a new mine or an expansion project, the involvement of social and environmental specialists in project design, and stage-gate reviews has historically occurred only after the core technical design decisions have been made, and engagement is limited to mitigation and communication strategies. Not surprisingly, some projects have faced opposition and have been delayed by community concerns regarding environmental or social impacts, real or perceived. To address this risk, Anglo American has incorporated social and environmental criteria in its capital projects requirements since 2010.

Social conflicts and potential environmental threats typically manifest during the early stages of project development and often escalate, impacting on capital costs in the project phase, and operating costs and productivity during the operating phases.

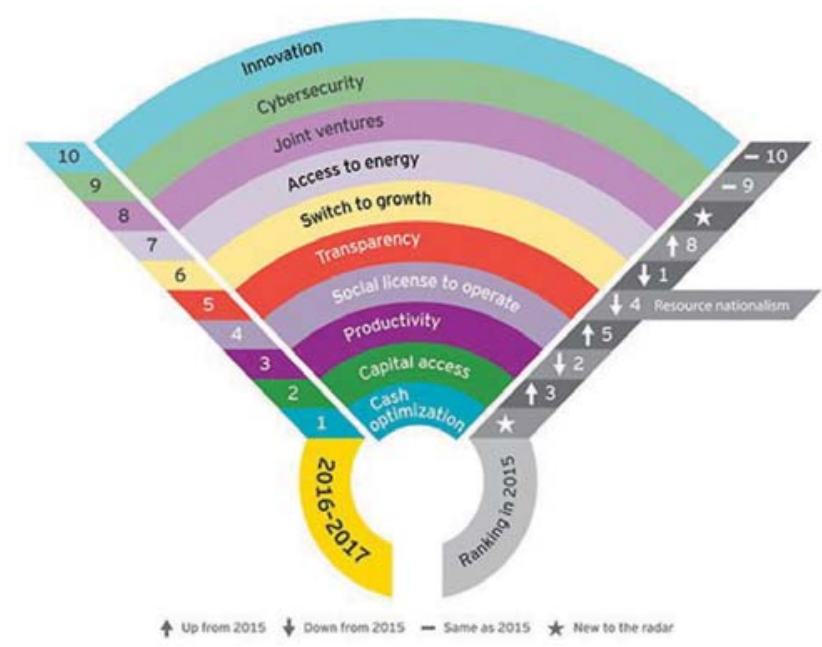

Figure 2-Business risk radar for mining and metals industry 2016-2017 (EYGM, 2016) 


\section{Incorporation of the socio-cultural dimension into strategic long-term planning of mineral assets}

Incorporating social considerations in the project design process is seldom regarded as an optimization objective in its own right, but usually as a time schedule constraint imposed by the engagement process. This can result in a perception that focusing on social or environmental issues will incur costs, and delay, or even potentially suspend the project.

Project assessment, capital investment prioritization, and portfolio optimization rely heavily on discounted cash flow techniques, primarily net present value (NPV). It is often argued that the discount factor applied in the valuation accounts for risks associated with the socio-cultural licence to operate, but this approach does not adequately capture potential project competitiveness.

Creating flexibility in the project development process and schedule may better incorporate socio-cultural concerns. An approach that balances the trade-off between NPV estimation and social and environmental impacts (positive and negative) to evaluate several project options can produce a more realistic business analysis (Corder et al., 2015). The ability to systematically assess the difference between a project option with a higher NPV estimate and higher social risk profile and an alternative option with a lower NPV estimate and lower social risk profile can be of great value for decision-makers. For example, decision-making can be facilitated by defining the value associated with increased spend on dust control to reduce the impact on local communities and the extent of associated community interruptions relative to the base option.

Early identification of probable social and environmental issues through risk assessments and quantification of the impacts on capital, cost, and time schedules allows the effective inclusion of socio-cultural elements into discounted cash analyses. This approach allows potential threats to be identified earlier in the process, with improved mitigation. Considerable opportunity therefore lies in appropriately including socio-cultural aspects within the strategic planning and option valuation process so as to allow effective decisionmaking and reduced execution risk.

An effective strategic long-term planning process identifies, defines, and values the optimized intersect between a techno-economic solution and the probable social, environmental, and cultural impacts of the development on the local community. Given the risks to both the business and affected stakeholders, it is critical to include socio-cultural considerations in the strategic planning and option valuation process to enable effective decision-making and reduce execution risk.

\section{Social performance and the socio-cultural licence to operate}

For every community there exists a set of specific physical, social, cultural, economic, and historical circumstances that drive beliefs, customs, practices, and behaviour. This is the socio-cultural context within which a mutual solution should be found to deliver sustainable value, to both the mining operations and the community, over the anticipated life of operations and subsequent closure. Critical to this is developing an understanding of what the socio-cultural context is, as it pertains to the development or expansion under consideration.
The significance of the socio-cultural dimension in strategic long-term planning is captured in the following statement by Chris Griffith, CEO of Anglo American Platinum Limited (2015);

'We have to work to build stronger relationships with our communities, deliver real and lasting benefits to them, and demonstrate that we are mitigating the impact on their lives as a result of our operations'.

Achieving this intent requires:

> Impact management-Maximizing the positive influences of mining activities on local development and effectively managing any adverse impacts. This includes respecting and protecting the human rights, livelihoods, culture, and beliefs of communities impacted by mining and processing operations

> Engagement-Building resilient relationships with key stakeholders

> Fairness-Treating stakeholders in a fair and transparent manner. This includes providing access to mechanisms for redress, such as grievance procedures.

To achieve these objectives, Anglo American has developed and implemented the Anglo American Social Way (AASW) (Anglo American, 2014), which defines the governing framework for social performance. The AASW is structured around the following core principles.

- Delivery of a lasting and positive contribution to affected communities - It is recognized that host countries and communities seek significant socioeconomic benefits from the development of natural resources and that the support of affected and interested stakeholders is fundamental to long-term success.

> Management of risks and impacts-Recognition that a core part of delivering a positive contribution is the effective management of actual and potential negative social impacts. There is therefore a need to avoid and prevent negative social impacts and, where appropriate, mitigate such impacts.

> Respect for human rights-Recognition that effective social performance is intrinsically linked with respect for human rights. This means, in practice, avoiding, preventing, mitigating, and where appropriate remediating adverse human rights impacts.

> Engagement with affected and interested stakeholders - To engage with affected, potentially affected, and interested stakeholders in a transparent manner to ensure that they are able to express their views on positive opportunities, risks, adverse impacts and prevention and mitigation measures and to ensure that we are able to consider and respond in a proactive way.

- Empower vulnerable and marginalized groups-To acknowledge that potentially vulnerable groups in affected communities could be disproportionately impacted or less able to benefit from activities due to the fact that they are marginalized, historically disadvantaged, and disempowered.

> Integration of social performance within relevant operational processes-Effective social performance requires coordination between business units and business functions, suppliers and contractors. 


\section{Incorporation of the socio-cultural dimension into strategic long-term planning of mineral assets}

The AASW also sets out ten operational requirements for managed sites to ensure that socio-cultural issues are integrated into core business and LoM planning:

> Social risk and impact management-To manage sociopolitical risks and impacts (including human rights)

- Social performance strategy and social management plan-To develop a long-term approach to managing socio-political issues that supports the resource development plan and LoM plans

> Stakeholder engagement-To build resilient relationships with stakeholders

> Socio-economic development-To deliver a lasting, positive contribution to communities

- Social commitment management-To ensure delivery on commitments made to stakeholders

> Social incident management-To manage social incidents (including complaints) in a fair and transparent way

> Community health, safety, and security managementTo protect the health, safety, and security of local stakeholders

> Contractors, suppliers, and other business partnersTo manage socio-political risks and impacts of contactors/suppliers/business partners

> Social performance resourcing-To secure the necessary resources (human and financial) to manage social performance

> Context-specific requirements (resettlement, cultural heritage, indigenous peoples, benefit sharing)-To ensure that context-specific issues are effectively managed. through:

Effective application of the AASW principles is achieved

> Resourcing and appropriate skilling of staff

> Effective and inclusive engagement with local stakeholders

> Proactive identification, assessment, and management of activities consistent with the objective of avoiding or minimizing negative impacts

> Having an integrated approach to socio-economic development focused on leveraging core business activities in order to maximize positive development contributions to communities.

\section{Mogalakwena Platinum Mine - an example}

At Anglo American Platinum Limited, socio-cultural perspectives are integrated into the resource development planning (RDP), life of mine (LoM) planning processes, and the Anglo American operating model.

Mogalakwena Platinum Mine in Limpopo Province provides an example of this integration, where the general manager and senior leadership team have identified the longterm socio-cultural risks and opportunities in the broader operating environment for integration into the LoM planning. These socio-cultural issues are wide ranging and include land access, socio-economic development, and environmental impact mitigation. These issues are assessed through an overall organizational risk management process, which includes the bow-tie analysis methodology, to identify the root causes and their appropriate controls (preventative and mitigating). Bow tie analysis is a risk evaluation approach that analyses and demonstrates causal relationships. The application of the bow-tie methodology has been adapted to:

> Reflect the complexities of socio-cultural issues

- Map the often inter-connected root causes

> Distinguish the proximate triggers of an incident from the underlying root causes.

Once the socio-cultural issues are understood through the bow-tie analysis, they are formally integrated into the LoM planning with a five-year outlook and operating model implementation.

Additionally, the longer-term RDP includes the sociocultural scenarios that could affect the extraction of the resource. At Mogalakwena, in particular, access to land has been identified as a potential issue and the short-, medium-, and long-term risks and opportunities are continually assessed. This includes scenarios associated with population growth trends, the development of other industries that place demands on land, government priorities for land usage (including zoning), emerging regulation (e.g. potential biodiversity offset requirements), the sustainability of local agricultural practices, impacts of climate change on land productivity, etc. These scenarios need to be considered against opportunities for technology development that have the potential to significantly alter the land use requirements of mining.

Through this process, the management of socio-cultural risks and opportunities is integral to the business. A critical success factor is the ability of general managers and senior leadership teams to consider the often unpredictable and sometimes uncontrollable scenarios presented by the mine's broader operating context.

\section{Conclusion}

In order for a minerals and metal company to create sustainable value from mineral assets, it is necessary to:

> Optimize the composition of the mineral asset portfolio to align with strategic and business objectives

> Create and operate long-term assets within an anticipated long-term business environment

> Create and retain flexibility of short-term tactical response that allows effective response to short-term shifts in the business environment, i.e. a production mix that allows output to be varied in response to short-term market variations, within a long-term context

> Have an integrated approach to socio-economic development, focused on leveraging core business activities in order to maximize positive development contributions to communities.

Given the increasing significance of socio-cultural related risks to the minerals industry, there is a fundamental need to adapt the drivers and principles for strategic long-term planning. There is a critical need for meaningful engagement and input into the front end of capital project development (evaluation, prioritization, and execution) as well as longterm planning (LoM and RDP) to develop relevant assumptions, inputs, and constraints in order to secure and maintain the social licence to operate. 


\section{Incorporation of the socio-cultural dimension into strategic long-term planning of mineral assets}

First and foremost, this requires a material shift in perspective regarding the potential impact of environmental, social, and cultural issues on project risk and long-term viability. Secondly, the effective integration of socio-cultural dimensions into planning and execution of mining projects requires resourcing and appropriate skilling of staff, effective and inclusive engagement with local stakeholders, and proactive identification, assessment, and management of activities consistent with the objective of avoiding or minimizing negative impacts while ensuring an integrated approach to socio-economic development, focused on leveraging core business activities in order to maximize positive development contributions to communities.

\section{References}

Anglo American Platinum Ltd. 2015. CEO internal communication. Anglo American PLC. 2014. Social Way version 2. Anglo American Services UK Ltd.

EYGM LIMITED. 2016. Top ten business risks facing mining and metals, 20162017. http://www.ey.com/Publication/vwLUAssets/EY-business-risks-inmining-and-metals-2016-2017/\%24FILE/EY-business-risks-in-miningand-metals-2016-2017.pdf

Corder, G., Kemp, D., Brereton, D., and BAngerter, P. 2015. Integrating social and environmental aspects in project design. AusIMM Bulletin, December 2015.

SMITH, G.L. 2012. Presidential address: Strategic long-term planning in mining Journal of the Southern African Institute of Mining and Metallurgy, vol. 112 , no. 93 . pp. 1-14. 